\title{
Long Term Outcome for OnabotulinumtoxinA (Botox) Therapy in Chronic Migraine: A 2-Year Follow up of Patients Attending the Hull (UK) Migraine Clinic
}

\section{Fayyaz Ahmed ( $\nabla$ fayyaz.ahmed@hey.nhs.uk)}

University of Hull https://orcid.org/0000-0002-2746-0889

\section{Alina Buture}

Hull University Teaching Hospitals NHS Trust

Taukir Tanvir

Hull University Teaching Hospitals NHS Trust

Modar Khalil

Hull University Teaching Hospitals NHS Trust

Short report

Keywords: Botox, chronic migraine, long-term, OnabotulinumtoxinA, responder, 2-year outcome

Posted Date: August 25th, 2020

DOI: https://doi.org/10.21203/rs.3.rs-63551/v1

License: (c) (1) This work is licensed under a Creative Commons Attribution 4.0 International License.

Read Full License 


\section{Abstract}

\section{Objective}

The objective of this prospective analysis was to determine the long-term outcome of patients diagnosed with chronic migraine who were treated with OnabotulinumtoxinA for the prevention of chronic migraine.

\section{Background}

The long-term outcomes of patients treated with OnabotulinumtoxinA remains uncertain, including information on the number of cycles and duration of OnabotulinumtoxinA needed to successfully convert chronic migraine to episodic migraine, development of resistance to treatment and sustainability of response after stopping treatment.

\section{Methods}

A total of 655 adult patients diagnosed with chronic migraine who received OnabotulinumtoxinA at the Hull Migraine Clinic were followed up prospectively for a minimum of 2 years. OnabotulinumtoxinA was delivered as per the PREEMPT study protocol and patients were asked to keep a headache diary for at least 30 days prior to and continuously after receiving OnabotulinumtoxinA. The primary outcome was either the number of patients who achieved $a \geq 50 \%$ reduction in headache days or migraine days or an increment in crystal clear days twice that of baseline in a 30-day period. Patients were also assessed for analgesic medication overuse.

\section{Results}

Treatment data were available for 655 patients who commenced treatment between July 2010 and October 2016 and followed for at least 2 years (24-70 months). Of the 655 patients, 380 patients responded to treatment after two cycles and went on to receive the third cycle. Of these, 152 patients were still on active treatment at 2 years. Of the 228 patients who stopped treatment, 112 were successfully converted to episodic migraine and showed a sustained response, 28 reverted to chronic migraine after the initial response inspite of continuing treatment (developed resistance), 14 were lost to follow up and 61 patients after achieving remission relapsed after a mean of 9 months (range 4-24 months) and recommenced treatment with OnabotulinumtoxinA.

\section{Conclusion}

After a minimum of 2 years, $29.4 \%$ of patients with chronic migraine who initially responded to treatment were successfully converted to episodic migraine and maintained a sustained response. Forty percent of the initial cohort of responders continued therapy with OnabotulinumtoxinA to manage their chronic migraine.

\section{Background}


Chronic migraine (CM) affects approximately $2 \%$ of the general population[i] and is considered the most disabling form of the disorder, with a substantial impact on patient quality of life.[ii]

Patients with $\mathrm{CM}$ require prophylactic therapy to reduce the frequency of migraine attacks.[iii] OnabotulinumtoxinA (onabotA; Botox ${ }^{O}$ ) is a formulation of botulinum toxin type A administered by intramuscular injection, and is specifically approved for the prevention of headaches in adults with $\mathrm{CM}$ in the European Union and North America.[iv][V],[vi]The efficacy and safety of OnabotulinumtoxinA in adults with CM has been demonstrated in the Phase III Research Evaluating Migraine Prophylaxis Therapy (PREEMPT) clinical trial programme,[vii],[viii],[ix],[x],[xi] In addition, recent meta-analyses and systematic literature reviews of randomised, double-blind, placebo-controlled trials have concluded that botulinum toxin $A$ is an effective treatment for reducing the frequency of migraine episodes in patients with CM.[xii]' $[\mathrm{xiij],[xiv]} A$ s a result, OnabotulinumtoxinA is being increasingly used in the management of $\mathrm{CM}$ in clinical practice and has been guideline recommended as an effective and well-tolerated treatment of CM.[xv]

OnabotulinumtoxinA was approved in the UK by the Medicine and Healthcare product Regulatory Agency (MHRA) in July 2010[xvi] and by the US Food and Drug Administration (FDA) in October 2010[xvii] for the treatment of CM. In the UK, the National Institute for Health and Care Excellence (NICE) have approved the use of botulinum toxin type A on the National Health Service (NHS) for the prophylaxis of headaches in adults with $\mathrm{CM}$ (defined as headaches on $\geq 15$ days per month of which $\geq 8$ days are with migraine)[xviii] that has not responded to $\geq 3$ prior pharmacological prophylaxis therapies and whose condition is appropriately managed for medication overuse.[xix] It is currently recommended that treatment with botulinum toxin type A should be stopped in people whose condition is not adequately responding to treatment (defined as a $<30 \%$ reduction in headache days per month after two treatment cycles) or has changed to episodic migraine (defined as $<15$ headache days per month) for 3 consecutive months. 19 It is also recommended that patients currently receiving botulinum toxin type $A$ should have the option to continue treatment until they and their clinician consider it appropriate to stop.19

There remains limited information on the long-term outcomes for patients with $\mathrm{CM}$ treated with OnabotulinumtoxinA in real life clinical practice. It remains uncertain as to the number of cycles required to achieve therapeutic outcome of episodic migraine; the proportion with sustained remission and those who relapse; patients reverting to $\mathrm{CM}$ despite continuing treatment (resistance) and those stopping treatment with poor tolerability and side effects developing after few cycles.

This is a long-term follow up of an original prospective real-life analysis in an adult patient population. $[\mathrm{xx}]$ The aim of the current analysis was to determine the outcome at 2 years in this patient population using clearly defined responder criteria.

\section{Methods}


This prospective analysis was conducted at the Hull Migraine Clinic (Hull Royal Infirmary and Spire Hospital Hull and East Riding). Adult patients were eligible for inclusion if they had CM, defined as headache on $\geq 15$ days/month for $\geq 3$ months, of which $\geq 8$ days meet criteria for migraine with or without aura or respond to migraine-specific treatment.[i] All patients had tried and failed at least one oral preventive migraine therapy. Full details of the inclusion criteria have been published previously.20

Patients received OnabotulinumtoxinA injections as per the PREEMPT study protocol:11 155 units of OnabotulinumtoxinA were injected intramuscularly into 31 injection sites around the head and neck. Patients were prospectively followed for at least 2 years during the period of July 2010 and September 2018). Before treatment commenced, patients were asked to maintain a headache diary for at least 30 days prior to and continuously after receiving treatment with OnabotulinumtoxinA. The Hull Headache Diary (Figure 1) was used to capture data on headache, painkillers and quality of life.[ii] The continuous diary filling was mandatory to assess response to treatment in order to determine whether patients were offered a repeat treatment.

Patient continued to maintain the headache diary and their response to treatment together with data on headache days, migraine days and crystal clear days were recorded at each visit. For the purpose of repeat treatment, the responder criteria defined by both the NICE and Hull Headache Clinic were used. NICE defined a responder as one with $\geq 30 \%$ reduction in headache days' frequency after two treatment cycles, without emphasis on the severity of headache, i.e., number of migraine days.19 The Hull Headache Clinic criteria defined responder as $\geq 50 \%$ reduction in either headache days or migraine days and/or an increment in crystal clear (headache free) days twice that of baseline in a 30-day period, provided they had at least three headache free days prior to treatment. Those with less than three clear days required to achieve at least 6 headache free days post treatment to be classed as responders. Both NICE and Hull criteria were followed for the negative stopping rule, that is if there is no response in the first two cycles, a third treatment was not given. A modified positive stopping rule was used where treatment could be stopped if the headache days remained $<10$ days per month for 3 consecutive months following treatment. Patients were restarted on treatment if they had $>15$ headache days for $>3$ months (relapsed). Treatment was stopped in those that reverted to baseline despite continuing treatment with OnabotulinumtoxinA (developed resistance). Treatment was also stopped if patient did not want to continue treatment for reasons such as pregnancy or intolerance to treatment. The extent of analgesic consumption, days off work quality of life score (HIT-6) and both $50 \%$ and $75 \%$ responder rate were also evaluated.

\section{Statistical analysis}

The details of the statistical analysis have been reported previously.20 Briefly, the primary aim of the analysis was to compare the difference between outcome measurements made before and after treatment. All outcomes were measured on a continuous scale.

\section{Results}




\section{Patient demographics}

A series of 972 adult patients were treated (completed cycles) between July 2010 and September 2018 and received 5745 cycles. ${ }^{9}$ Full data were available for 851 patients. Treatment data for at least 2 years (24-70 months) were available for 655 patients who commenced treatment between July 2010 and October 2016 (Table 1).

\section{Headache days, migraine days and crystal clear (headache-free) days}

The mean number of headache days, migraine days and crystal clear (headache-free) days at baseline and after treatment are shown Table 2 . The percentage of patients achieving $a \geq 50 \%$ reduction in headache days, migraine days and $a \geq 2$-fold increase in crystal clear days with treatment was $22.6 \%$, $39.1 \%$ and $38.8 \%$, respectively. There was also a significant improvement in the Headache Impact Test- 6 (HIT-6) score after treatment versus baseline $(p<0.001$, Table 1$)$.

\section{Treatment responses after 2 years}

Of the 655 patients followed for at least 2 years, 380 (58\%) fulfilled the Hull criteria (47.8\% fulfilled the NICE criteria for responder) at Cycle 2 of treatment and were allowed to continue to Cycle 3 of treatment, and 275 (42\%) patients stopped treatment as per the negative rule (Figure 2).

From the cohort of 380 patients who met the responder criteria, $152(40 \%)$ patients were still on treatment at 2 years (Figure 2). Of the responders who stopped treatment $(n=228), 112(49.1 \%)$ stopped after successfully converted to episodic migraine; 28 (12.3\%) reverted to CM while still on treatment (Figure 2); 14 were lost to follow up and 13 stopped treatment due to pregnancy. Sixty-one (26.7\%) patients who were successfully converted to episodic migraine relapsed after an average of 9 months (range 4-24 months) and recommenced treatment. Hence from the original cohort of 380 responders, $112(29.4 \%)$ continued to show a sustained response at 2 years (Figure 2).

\section{Analgesic medication overuse}

The median change in analgesic use in terms of the number of days of non-triptan analgesics and triptans needed was assessable in 827 of the total 972 patients. Use of non-triptan analgesics before treatment had an interquartile range of 6 to 22 days per month with a median of 12 days before treatment and that of triptan use had an interquartile range of 0-7 with a median of 1 day per month before treatment.

There was a significant reduction in the number of days of both non-triptans and triptans after treatment versus baseline (Table $3 ; p<0.001$ ). Forty one percent of patients were able to achieve $a \geq 50 \%$ reduction in non-triptan analgesic use and $46 \%$ were able to achieve $a \geq 50 \%$ reduction in triptan use after treatment. 
There was also a significant reduction in the number non-triptan analgesic days after treatment versus patients who did not overuse medication at baseline $(p<0.001$; Table 4$)$. The number of triptan days after treatment did not differ between the two patient groups.

\section{Discussion}

The results of this prospective real-life analysis of patients with CM complement outcomes seen in randomised controlled trials and other real-world analyses, lending additional support for the use of OnabotulinumtoxinA in the management of $\mathrm{CM}$, and providing valuable information on treatment practices and patient characteristics among unselected patients.

In the primary analysis of this patient cohort (254 patients), OnabotulinumtoxinA was shown to significantly reduce the number of headache and migraine days, and increased the number of headache free days versus pre-treatment levels. 20 In the current 2-year follow up, these benefits of treatment were shown to continue in a substantial proportion of the patients. Of the cohort of initial responders $(\mathrm{N}=380)$ after two cycles of Botox, $45.5 \%(\mathrm{~N}=173)$ were converted to episodic migraine of which the benefit was sustained in $65 \%(\mathrm{~N}=112)$ whilst $35 \%(\mathrm{~N}=61)$ relapsed after an average of 9 months (range $4-24$ months).

Few patients became resistant to therapy and reverted to $\mathrm{CM}$ while still on treatment (12.3\%), others either lost to follow up or stopped due to pregnancy. Importantly, the HIT-6 score was significantly improved at 2 years versus baseline. This persistence in HIT-6 reduction over time indicates a stable and long-term improvement in the impact of headache on patients' ability to function.

The results of this analysis support previous observations that loss of response to botulinum toxin A for $\mathrm{CM}$ after the first year is rare.[i] The outcomes observed also align with those of previous long-term follow ups in real-life clinical scenarios. In a 2-year follow up of 123 patients in the US, it was reported that $67 \%$ of patients with $\mathrm{CM}$ were still on treatment after 2 years. [ii] In this study, $25 \%$ of patients were able to stop treatment and remain free of $\mathrm{CM}$ for a minimum of 6 months, and $8 \%$ of patients stopped responding to therapy while still on treatment. However, it should be noted that, in this study, the definition of responder was not clearly defined, negative and positive stopping rules were not clear and treatment was funded via insurance reimbursement. In a second US study, the Chronic Migraine OnabotulinumtoxinA Prolonged Efficacy open Label (COMPEL) study, the consistency of the efficacy and the long-term safety and tolerability of OnabotulinumtoxinA for the prevention of headache in 716 patients diagnosed with $\mathrm{CM}$ (treated every 12 weeks over 2 years) were analysed.[iii] A significant and sustained benefit of treatment was reported. A limitation of this study was the drop out of nearly half of the patients with reasons not clearly defined. Those who did benefit from treatment were continued on treatment for 2 years. Although the study evaluated long term efficacy, the need for continuation of treatment was not analysed. Finally, in two 3-year follow-ups of treatment of 90 patients in Italy and 65 patients in Greece, respectively, OnabotulinumtoxinA was found to be an effective and well tolerated treatment for CM. [iv],[v] OnabotulinumtoxinA did not show any incoming tolerance and its effectiveness was confirmed to be long-lasting, generating stable improvements in headache symptoms and patients' quality of life. 25 
The degree of analgesic use before and after treatment was studied and reported earlier. The median number of painkiller days before treatment was 12 (interquartile range of 6-22). This was reduced to 7 days (range 2-13) after treatment. The frequent or regular use of analgesics and anti-migraine drugs can make headache more frequent and induce the transformation of episodic to $\mathrm{CM}$.[vi] Medication overuse was highly prevalent in the patient population included in this prospective analysis, with $54 \%$ of patients overusing various analgesics (triptans and/or other analgesics [paracetamol, nonsteroidal antiinflammatory drugs and opioids]). OnabotulinumtoxinA offered an effective prophylactic treatment option in these patients and the results of the current analysis confirmed the outcomes from earlier studies that demonstrated that OnabotulinumtoxinA was effective in individuals regardless of medication overuse at baseline.25,[vii],[viii],[ix]

The current prospective analysis provides an insight into the long-term outcomes in 655 patients diagnosed with $\mathrm{CM}$ prophylactically treated with OnabotulinumtoxinA in a real-life clinical setting that measured not only treatment response using defined responder criteria, but also analysed the frequency of headache days and the severity of the headaches. The prospective analysis also provided important insights into the sustainability of the response to treatment and the degree of resistance to treatment over the long term. As with the primary patient population, the patient cohort in this analysis is believed to be representative of patients seen in daily clinical practice at an average tertiary headache centre in the UK and is concordant with previous observations in real-life long-term clinical studies assessing the efficacy of OnabotulinumtoxinA for the treatment of CM.[x]

The strength of this prospective analysis was the large sample size that was representative of the patients with CM typically seen in daily clinical practice in a tertiary headache centre of UK. However, as with any prospective real-life analysis, there was a risk of confounding bias and lack of randomisation, and the lack of a control group meant it was not possible to quantify a placebo effect. The second limitation is that this is a single centre study, which may reflect practice bias of the clinician in the centre. The third limitation is that the study was conducted in the UK where treatment is funded centrally by the $\mathrm{NHS}$ and start and stopping rules of the treatment may differ from other countries where limitations and reimbursement rules may be different. The 2-year data does not include patients that could have relapsed or become resistant beyond 2 years and may have had a different outcome. The adverse effects of the toxin was only evaluated during the second cycle, although we believe that this would not have been higher subsequently as none of the patients stopped treatment due to adverse effects and the number of patients that were lost to follow up were very small.

\section{Conclusions}

OnabotulinumtoxinA continues to be a valuable addition to current treatment options for patients who are difficult to treat or intolerant of traditional oral prophylactic therapies and who have received treatment for at least 2 years and provides a lasting remission from oral treatment in a considerable number of patients. 


\section{Abbreviations}

CM Chronic migraine

FDA US Food and Drug Administration

MHRA Medicine and Healthcare product Regulatory Agency

NHS National Health Service

NICE National Institute for Health and Care Excellence

PREEMPT Phase III Research Evaluating Migraine Prophylaxis Therapy

\section{Declarations}

\section{Ethics approval and consent to participate}

The study protocols were reviewed and approved by the appropriate institutional review board for each of the study sites. The studies were conducted according to Good Clinical Practice and the Declaration of Helsinki guidelines. Patients provided written informed consent before undergoing study procedures.

\section{Availability of data and materials}

The datasets used and/or analysed during the current study are available from the corresponding author on reasonable request.

\section{Competing interests}

Fayyaz Ahmed has received honorarium for being on the advisory board of Allergan, Novartis, TEVA, Eli Lilly, Electrocore, Eneura paid to the charitable organisations i.e., British Association for the Study of Headache (BASH), Migraine Trust (MT) and Anglo-Dutch Migraine Association (ADMA).

Alina Buture, Modar Khalil and Taukir Tanvir have no competing interests to declare.

\section{Funding}

The study was funded by the Headache Research Trial fund at the Department of Neurosciences, Hull York Medical School and the Hull University Teaching Hospitals.

\section{Authors' contributions}

Fayyaz Ahmed conceptualised and set the study design, Data was collected by Fayyaz Ahmed, Modar Khalil, Taukir Tanvir and Alina Buture and Fayyaz Ahmed, and Modar Khalil analysed and interpreted the data. All authors contributed in the drafting and revision of the manuscript. 
Writing and editorial assistance was provided to the authors by Dr Vanessa Lane, PhD, of Jango Communications Limited, UK and funded by Allergan (now AbbVie). Allegan had no input into the manuscript or study data. All authors met the ICMJE authorship criteria.

\section{Acknowledgements}

The authors would like to thank Dr Vanessa Lane for her assistance in the preparation of the manuscript.

\section{References}

1. Natoli JL, Manack A, Dean B, Butler Q, Turkel CC, Stovner L, Lipton RB. Global prevalence of chronic migraine: A systematic review. Cephalalgia. 2010;30:599-609.

2. Bigal ME, Serrano D, Reed M, Lipton RB. Chronic migraine in the population: burden, diagnosis, and satisfaction with treatment. Neurology. 2008;71:559-66.

3. Agostoni EC, Barbanti P, Calabresi P, Colombo B, Cortelli P, Frediani, F, et al. Current and emerging evidence-based treatment options in chronic migraine: a narrative review. J Headache Pain. 2019;20:92.

4. Botox (onabotulinumtoxinA), Summary of product Characteristics. Available from: https://www.medicines.org.uk/emc/product/859/smpc (Accessed 11 December 2019).

5. Health Products Regulatory Authority. BOTOX 50, 100, 200 Allergan Units, powder for solution for injection (BOTULINUM TOXIN TYPE A): IE/H/0113/001-003: IPAR. Available from: https://www.hpra.ie/img/uploaded/swedocuments/LicenseSPC_PA0148-060003_04052017103240.pdf (Accessed 11 December 2019).

6. Allergan Inc. BOTOX (onabotulinumtoxinA) for injection, for intramuscular, intradetrusor, or intradermal use: US prescribing information. Available from: https://www.accessdata.fda.gov/drugsatfda_docs/label/2017/103000s5302lbl.pdf (Accessed 11 December 2019).

7. Aurora SK, Winner P, Freeman MC, Spierings EL, Heiring JO, DeGryse RE, et al. OnabotulinumtoxinA for treatment of chronic migraine: pooled analyses of the 56-week PREEMPT clinical program. Headache. 2011;51:1358-73.

8. Dodick DW, Turkel CC, DeGryse RE, Aurora SK, Silberstein SD, Lipton RB, et al, PREEMPT Chronic Migraine Study Group. OnabotulinumtoxinA for treatment of chronic migraine: pooled results from the double-blind, randomized, placebo-controlled phases of the PREEMPT clinical program. Headache. 2010;50:921-36.

9. Aurora SK, Dodick DW, Turkel CC, DeGryse RE, Silberstein SD, Lipton RB, et al, PREEMPT 1 Chronic Migraine Study Group. OnabotulinumtoxinA for treatment of chronic migraine: results from the double-blind, randomized, placebo-controlled phase of the PREEMPT 1 trial. Cephalalgia. 2010;30:793-803. 
10. Diener HC, Dodick DW, Aurora SK, DeGryse RE, Silberstein SD, Lipton RB, et al, PREEMPT 1 Chronic Migraine Study Group. OnabotulinumtoxinA for treatment of chronic migraine: results from the double-blind, randomized, placebo-controlled phase of the PREEMPT 2 trial. Cephalalgia. 2010;30:804-14.

11. Blumenfeld A, Silberstein SD, Dodick DW, Aurora SK, Turkel CC, Binder WJ. Method of injection of onabotulinumtoxinA for chronic migraine: a safe, well-tolerated, and effective treatment paradigm based on the PREEMPT clinical program. Headache. 2010;50:1406-18.

12. Bruloy E, Sinna R, Grolleau JL, Bout-Roumazeilles A, Berard E, Chaput B. Botulinum toxin versus placebo: a meta-analysis of prophylactic treatment for migraine. Plast Reconstr Surg. 2019;143:239-50.

13. Herd CP, Tomlinson CL, Rick C, Scotton WJ, Edwards J, Ives NJ, et al. Cochrane systematic review and meta-analysis of botulinum toxin for the prevention of migraine. BMJ Open. 2019;9:e027953.

14. Mimeh H, Fenech Magrin AM, Myers S, Ghanem AM. A critical review of botulinum toxin type $A$ in the prophylactic treatment of chronic migraine in adults. Aesthet Surg J. 2019;39:898-907.

15. Bendtsen L, Sacco S, Ashina M, Mitsikostas D, Ahmed F, Pozo-Rosich P, Martelletti P. Guideline on the use of onabotulinumtoxinA in chronic migraine: a consensus statement from the European Headache Federation. J Headache Pain. 2018;19:91.

16. Medicine and Healthcare product Regulatory Agency (MHRA). Available from: www.mhra.gov.uk (Accessed 11 December 2019).

17. US Food and Drug Administration (FDA). Available from: www.fda.gov (Accessed 11 December 2019).

18. Headache Classification Committee of the International Headache Society (IHS) The international classification of headache disorders, 3rd edition. Cephalalgia. 2018;38:1-211.

19. National Institute for Health and Care Excellence (NICE). Botulinum toxin type A for the prevention of headaches in adults with chronic migraine. Technology appraisal guidance [TA260]. Published date: 27 June 2012. Available from: https://www.nice.org.uk/guidance/ta260 (Accessed 11 December 2019).

20. Khalil M, Zafar HW, Quarshie V, Ahmed F. Prospective analysis of the use of onabotulinumtoxinA (BOTOX) in the treatment of chronic migraine; real-life data in 254 patients from Hull, UK. J Headache Pain. 2014;15:54.

21. IHS. International Classification of Headache Disorders- (ICHD-3). Chronic migraine diagnostic criteria 2018. Available from: https://ichd-3.org/1-migraine/1-3-chronic-migraine/ (Accessed July 2020).

22. Ahmed F, Khalil M. Hull Headache Diary, 2013. http://www.bash.org.uk/about/headache-diary/ (Accessed 11 December 2019).

23. Gago-Veiga AB, Santos-Lasaosa S, Cuadrado ML, Guerreroe ÁL, Irimiaf P, Láinezg JM, Leiraet R, et al. Evidence and experience with onabotulinumtoxinA in chronic migraine: Recommendations for daily 
clinical practice. Evidencia y experiencia de bótox en migraña crónica: Recomendaciones para la práctica clínica diaria. Neurologia. 2019;34:408-17.

24. Rothrock JF. How effective is long term use of Botox for CM? Neurol Rev. 2011;19:18A.

25. Blumenfeld AM, Stark RJ, Freeman MC, Orejudos A, Adams AM. Long term study of the efficacy and safety of onabotulinumtoxinA for the prevention of chronic migraine; Compel Study. J Headache Pain. 2018;19:13.

26. Guerzoni S, Pellesi L, Baraldi C, Cainazzo MM, Negro A, Martelletti P, Pini LA. Long-term treatment benefits and prolonged efficacy of onabotulinumtoxina in patients affected by chronic migraine and medication overuse headache over 3 years of therapy. Front Neurol. 2017;8:586.

27. Vikelis M, Argyriou AA, Dermitzakis EV, Spingos KC, Makris N, Kararizou E. Sustained onabotulinumtoxinA therapeutic benefits in patients with chronic migraine over 3 years of treatment. J Headache Pain. 2018;19:87.

28. Diener HC, Holle D, Dresler T, Gaul C. Chronic headache due to overuse of analgesics and antimigraine agents. Dtsch Arztebl Int. 2018;115:365-70.

29. Blumenfeld; Negro A, Curto M, Lionetto L, Martelletti P. A two years open-label prospective study of OnabotulinumtoxinA $195 \mathrm{U}$ in medication overuse headache: a real-world experience. J Headache Pain. 2016;17:1

30. Schaefer SM, Gottschalk $\mathrm{CH}$, Jabbari B. Treatment of chronic migraine with focus on botulinum neurotoxins. Toxins (Basel). 2015;7:2615-28.

31. Frampton JE, Silberstein S. OnabotulinumtoxinA: A review in the prevention of chronic migraine [published correction appears in Drugs. 2018 Apr 20]. Drugs. 2018;78:5895-600.

32. Ahmed F, Gaul C, García-Moncó JC, Sommer K, Martelletti P on behalf of the REPOSE Principal Investigators. An open-label prospective study of the real-life use of onabotulinumtoxinA for the treatment of chronic migraine: the REPOSE study. J Headache Pain. 2019;20:26.

\section{Tables}

Table 1. Baseline characteristics 


\begin{tabular}{|ll|}
\hline Characteristic & Patients receiving onabotulinumtoxinA ( $\mathbf{N}=\mathbf{8 5 1})$ \\
\hline Gender, $\mathrm{n}(\%)$ & $693(81.4 \%)$ \\
Female & $158(18.6 \%)$ \\
Male & \\
\hline Age, median (range) & 45 years (17-96 years) \\
\hline Duration of chronic migraine, median (range) & 4 years $(0.5-67$ years) \\
\hline Failed three preventative treatments, $\mathrm{n}(\%)$ & $836(98.2 \%)$ \\
\hline Painkiller medication over-users, $\mathrm{n}(\%)$ & $448(52.6 \%)$ \\
\hline
\end{tabular}

Table 2. Median change headache outcome measures before and after treatment

\begin{tabular}{|c|c|c|c|c|c|c|c|}
\hline \multirow{2}{*}{ Outcome } & \multirow[t]{2}{*}{$\mathbf{N}$} & $\begin{array}{l}\text { Before } \\
\text { treatment }\end{array}$ & $\begin{array}{l}\text { After } \\
\text { treatment }\end{array}$ & \multirow{2}{*}{$\begin{array}{l}\text { Change } \\
\text { Median } \\
(95 \% \mathrm{Cl})\end{array}$} & \multirow[t]{2}{*}{$\begin{array}{l}\mathrm{p} \\
\text { value }\end{array}$} & \multirow{2}{*}{$\begin{array}{l}\geq 50 \% \\
\text { reduction } \\
\mathrm{N}(\%)\end{array}$} & \multirow{2}{*}{$\begin{array}{l}\geq 75 \% \\
\text { reduction } \\
\mathrm{N}(\%)\end{array}$} \\
\hline & & $\begin{array}{l}\text { Median } \\
\text { (IQR) }\end{array}$ & $\begin{array}{l}\text { Median } \\
\text { (IQR) }\end{array}$ & & & & \\
\hline $\begin{array}{l}\text { Headache } \\
\text { days }\end{array}$ & 851 & $\begin{array}{l}29(22, \\
30)\end{array}$ & $\begin{array}{l}21(12, \\
30)\end{array}$ & $-8(-9,-7)$ & $<0.001$ & $\begin{array}{l}192 / 851 \\
(22.6 \%)\end{array}$ & $\begin{array}{l}70 / 851 \\
(8.2 \%)\end{array}$ \\
\hline $\begin{array}{l}\text { Migraine } \\
\text { days }\end{array}$ & 851 & $\begin{array}{l}17(12, \\
23)\end{array}$ & $10(5,18)$ & $-6(-6,-5)$ & $<0.001$ & $\begin{array}{l}333 / 851 \\
(39.1 \%)\end{array}$ & $\begin{array}{l}129 / 851 \\
(15.2 \%)\end{array}$ \\
\hline $\begin{array}{l}\text { Crystal } \\
\text { clear days }\end{array}$ & 851 & $1(0,8)$ & $9(0,18)$ & $7(5,7)$ & $<0.001$ & $\begin{array}{l}\geq 2 \text {-fold } \\
\text { increase }\end{array}$ & $\begin{array}{l}\geq \text { 3-fold } \\
\text { increase }\end{array}$ \\
\hline $\begin{array}{l}330 / 851 \\
(38.8 \%)\end{array}$ & $\begin{array}{l}172 / 851 \\
(20.2 \%)\end{array}$ & \multirow[b]{2}{*}{$\begin{array}{l}\text { Mean } \\
\text { (SD) }\end{array}$} & \multirow[b]{2}{*}{$\begin{array}{l}\text { Mean } \\
\text { (SD) }\end{array}$} & \multirow[b]{2}{*}{$\begin{array}{l}\text { Change } \\
\text { Mean } \\
(95 \% \mathrm{Cl})\end{array}$} & \multirow[b]{2}{*}{$\begin{array}{l}p \\
\text { value }\end{array}$} & & \\
\hline Outcome & $\mathbf{N}$ & & & & & & \\
\hline HIT-6 score & 851 & $68(5)$ & $62(8)$ & $-6(-9,-5)$ & \multicolumn{2}{|l|}{$<0.001$} & \\
\hline \multicolumn{8}{|c|}{ Cl, confidence interval; HIT-6, 6-item Headache Impact Test; IQR, interquartile range. } \\
\hline \multirow{2}{*}{\multicolumn{2}{|c|}{ Outcome }} & \multirow[t]{2}{*}{$\mathbf{N}$} & Before treatment & \multicolumn{2}{|c|}{ After treatment } & Change & $p$ value \\
\hline & & & Median (IQR) & \multicolumn{2}{|c|}{ Median (IQR) } & Median (IQR) & \\
\hline \multicolumn{2}{|c|}{ Non-triptan analgesic days } & 448 & $20(15,30)$ & $10(5,1$ & & $-7(-15,0)$ & $<0.001$ \\
\hline \multicolumn{2}{|c|}{ Triptan days } & 448 & $4(0,10)$ & $2(0,6)$ & & $0(-5,0)$ & $<0.001$ \\
\hline
\end{tabular}


$\mathrm{IQR}$, interquartile range.

Table 4. Median change from baseline in analgesic days for medication over-users versus nonmedication over-users

\begin{tabular}{|c|c|c|c|c|c|}
\hline & Non-misusers & Misusers & p value & & \\
\hline Outcome & $\mathbf{N}$ & Median (IQR) & $\mathbf{N}$ & Median (IQR) & \\
\hline Non-triptan analgesic days & 379 & $0(-1,0)$ & 448 & $-7(-8,-6)$ & $<0.001$ \\
\hline Triptan days & 379 & $0(0,0)$ & 448 & $-2(-2,0)$ & 0.23 \\
\hline
\end{tabular}

IQR, interquartile range.

\section{Figures}

HULL HEADACHE CLINIC

F. DEPARTMENT OF NEUROLOGY

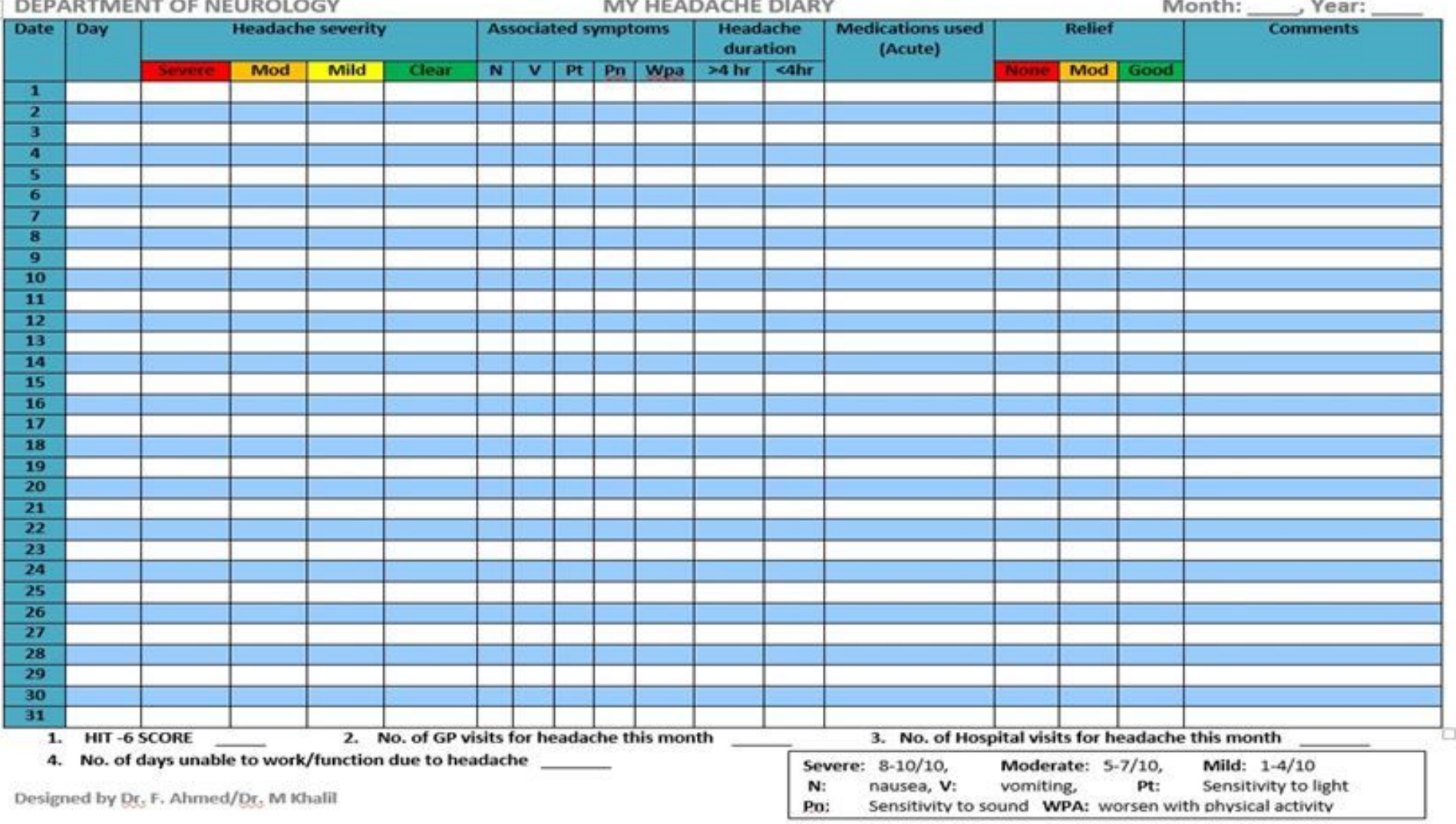

Figure 1

Hull headache diary 

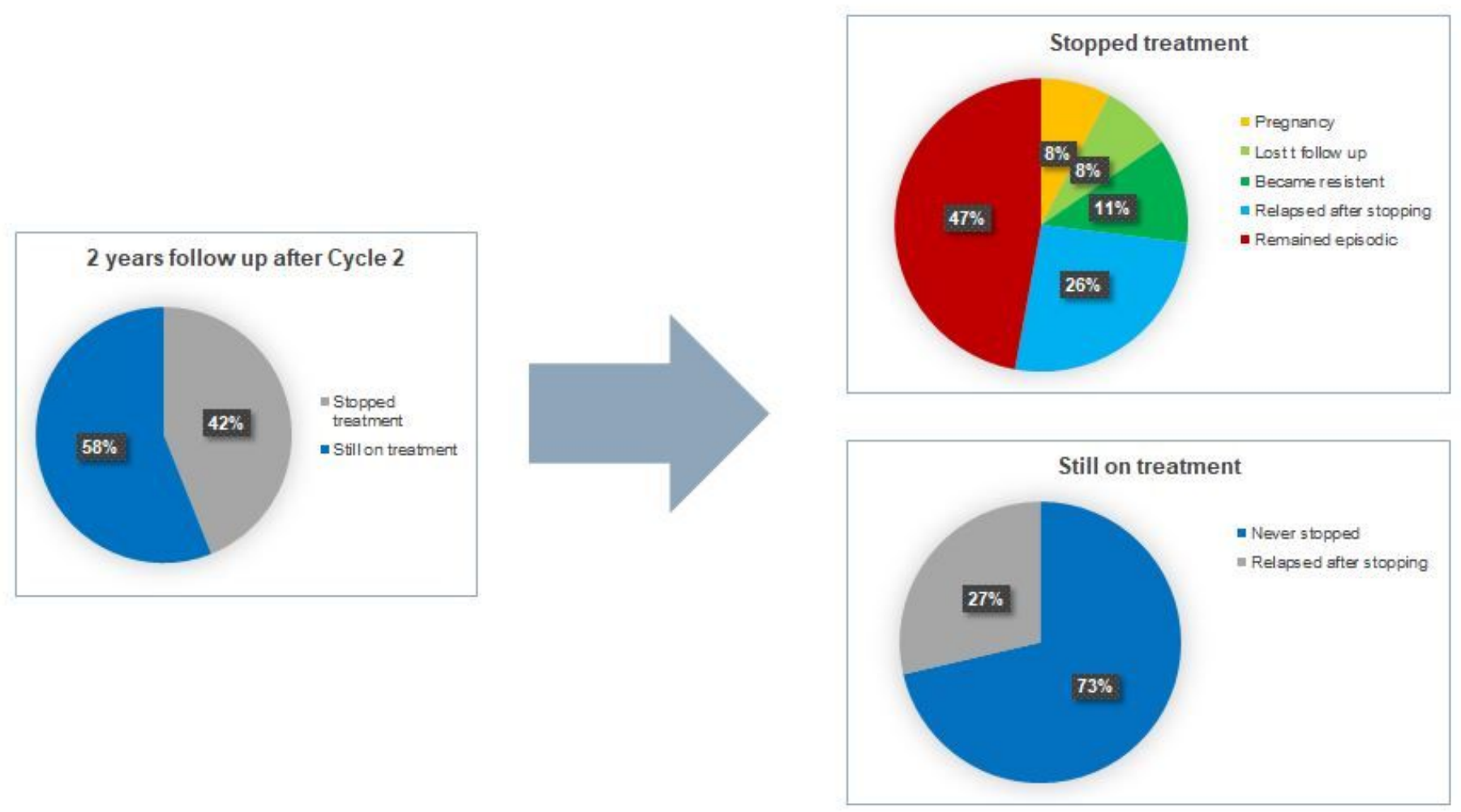

\section{Figure 2}

Summary of patients who stopped or continued treatment at 2 years follow up 